\title{
Hotspot mutations in common oncogenes are infrequent in nasopharyngeal carcinoma
}

\author{
NING JIANG $^{1 *}$, NA LIU $^{1 *}$, FAN YANG $^{5}$, QIMING ZHOU $^{1}$, RUIXUE CUI ${ }^{1}$, WEI JIANG ${ }^{1}$, \\ QINGMEI HE ${ }^{1}$, WENFEI LI ${ }^{2}$, YING GUO ${ }^{3}$, JING ZENG ${ }^{4}$, JINGPING YUN $^{4}$, XINCHUN CHEN $^{5}$, \\ BOPING ZHOU ${ }^{5}$, YING SUN ${ }^{2}$, HUIYUN WANG ${ }^{1}$, ZHUO G. $\mathrm{CHEN}^{6}$ and $\mathrm{JUN} \mathrm{MA}^{2}$ \\ ${ }^{1}$ State Key Laboratory of Oncology in Southern China; ${ }^{2}$ Department of Radiation Oncology; ${ }^{3}$ National Clinical Study Center \\ for Anticancer Drugs; ${ }^{4}$ Department of Pathology, Sun Yat-sen University Cancer Center, Guangzhou, Guangdong 510060; \\ ${ }^{5}$ Shenzhen Institute of Liver Diseases, The Third People's Hospital, Shenzhen, Guangdong 518112, P.R. China; \\ ${ }^{6}$ Department of Hematology and Medical Oncology, Winship Cancer Institute, \\ Emory University School of Medicine, Atlanta, GA 30322, USA
}

Received May 19, 2014; Accepted July 22, 2014

DOI: $10.3892 /$ or.2014.3376

\begin{abstract}
Oncogene mutations contribute to carcinogenesis and can provide potential therapeutic targets for clinical anticancer management. However, oncogene mutation patterns in nasopharyngeal carcinoma (NPC) have yet to be fully elucidated. To gain insight into mutation patterns in NPC, a high-throughput OncoCarta panel assay was used to determine 238 hotspot mutations across 19 common oncogenes in 8 NPC cell lines and 160 NPC patient samples from southern China. Statistical analyses were further conducted to identify associations between oncogene mutations and selected clinicopathological characteristics. In total, we identified 24 mutations across 11 oncogenes in $17(10.6 \%)$ NPC patients. Four patients exhibited mutations in at least one oncogene. We also identified a PIK3CA H1047R mutant in 7 NPC cell lines. In addition, oncogene mutations showed no correlation with either risk habits (smoking and drinking) or other clinical characteristics except for TNM stage. KIT mutations were associated with poorer overall and relapse-free survival. Furthermore, KIT mutations together with age and $\mathrm{N}$ stage were independent prognostic factors in NPC. Taken together, the present study is the first report on mutations in multiple oncogenes in NPC. We found that hotspot oncogene mutations are infrequent in NPC patients from southern China. The lack of hotspot mutations requires a comprehensive characterization of gene mutations in NPC for developing new therapeutic targets in the future.
\end{abstract}

Correspondence to: Dr Jun Ma, Department of Radiation Oncology, Sun Yat-sen University Cancer Center, 651 Dongfeng Road East, Guangzhou, Guangdong 510060, P.R. China

E-mail: majun2@mail.sysu.edu.cn

${ }^{*}$ Contributed equally

Key words: nasopharyngeal carcinoma, oncogene mutation, KIT, OncoCarta

\section{Introduction}

Nasopharyngeal carcinoma (NPC) is an endemic disease in southern China and Southeast Asia, with a global incidence of 84,400 new cases annually and a mortality of 51,600 in 2008 (1). After primary treatment with radiotherapy or chemoradiotherapy, a significant proportion of endemic NPC patients, particularly those with stage III or IV, relapsed locoregionally and/or systemically $(2,3)$. The median overall survival after recurrence is generally poor and ranges from 7.2 to 22 months (4-6). Therefore, new therapeutic strategies are required.

Cancer derives from the progressive accumulation of abnormalities in cellular DNA which provides growth advantages to cancer cells (7). Somatic mutations become useful targets and biomarkers in selecting personalized therapy for many solid tumors. For example, molecular driven therapeutic targets such as epidermal growth factor receptor (EGFR) and abnormal fusion of echinoderm microtubule-associated protein-like 4 and anaplastic lymphoma kinase (EML4-ALK) genes have resulted in a paradigm shift in the treatment of lung adenocarcinoma $(8,9)$. Furthermore, KRAS (Kirsten rat sarcoma viral oncogene homolog) and $B R A F$ (v-raf murine sarcoma viral oncogene homolog B) oncogene mutations are positively associated with resistance to anti-EGFR drugs $(10,11)$. Hence, current anticancer therapy depends more on the knowledge of genetic alterations in specific tumors.

Lifestyle exposure such as salted fish, EBV infection, smoking and drinking has consistently been linked to NPC risk (12), predicate on the hypothesis that genomic alternations as a result of lifestyle exposure may be a reason for NPC oncogenesis. Despite the fact that chromosomal abnormalities (13) together with amplification of certain oncogenes have been identified in NPC $(14,15)$, information regarding oncogene mutations in NPC is limited (16). Several studies demonstrated that oncogene phosphatidylinositol-4, 5-bisphosphate 3-kinase catalytic subunit $\alpha(P I K 3 C A)$ mutation was an uncommon event in NPC patients (17-19). No EGFR kinase domain mutation was found in 60 Moroccan NPC patients (20). BRAF and 
Table I. Clinicopathological characteristics of NPC patients $(n=160)$.

\begin{tabular}{|c|c|c|c|c|}
\hline \multirow[b]{2}{*}{ Characteristics } & \multirow[b]{2}{*}{$\begin{array}{l}\text { No. of patients } \\
\qquad(n=160)\end{array}$} & \multicolumn{2}{|c|}{ Mutation } & \multirow[b]{2}{*}{ P-value } \\
\hline & & $\begin{array}{l}\text { Absent } \\
\mathrm{n}(\%)\end{array}$ & $\begin{array}{l}\text { Present } \\
\mathrm{n}(\%)\end{array}$ & \\
\hline Age (years) ${ }^{\mathrm{b}}$ & 160 & $47.4 \pm 12.1$ & $47.9 \pm 11.5$ & $0.86^{\mathrm{c}}$ \\
\hline $\begin{array}{l}\text { Gender } \\
\text { Female } \\
\text { Male }\end{array}$ & $\begin{array}{r}36 \\
124\end{array}$ & $\begin{array}{r}32(88.9) \\
111(89.5)\end{array}$ & $\begin{array}{r}4(11.1) \\
13(10.5)\end{array}$ & 1.00 \\
\hline $\begin{array}{l}\text { Histology } \\
\text { Differentiated } \\
\text { Undifferentiated }\end{array}$ & $\begin{array}{r}6 \\
154\end{array}$ & $\begin{array}{r}5(83.3) \\
138(89.6)\end{array}$ & $\begin{array}{r}1(16.7) \\
16(10.4)\end{array}$ & 1.00 \\
\hline $\begin{array}{l}\text { Smokers } \\
\text { Yes } \\
\text { No }\end{array}$ & $\begin{array}{l}81 \\
71\end{array}$ & $\begin{array}{l}73(90.1) \\
62(87.3)\end{array}$ & $\begin{array}{l}8(9.9) \\
9(12.7)\end{array}$ & 0.58 \\
\hline $\begin{array}{l}\text { Alcohol consumpti } \\
\text { Yes } \\
\text { No }\end{array}$ & $\begin{array}{r}29 \\
123\end{array}$ & $\begin{array}{r}28(96.6) \\
107(87.0)\end{array}$ & $\begin{array}{c}1(3.4) \\
16(13.0)\end{array}$ & 0.25 \\
\hline $\begin{array}{l}\text { VCA-IgA } \\
<1: 80 \\
\geq 1: 80\end{array}$ & $\begin{array}{r}18 \\
141\end{array}$ & $\begin{array}{r}15(83.3) \\
127(90.1)\end{array}$ & $\begin{aligned} 3 & (16.7) \\
14 & (9.9)\end{aligned}$ & 0.64 \\
\hline $\begin{array}{l}\text { EA-IgA } \\
\quad<1: 10 \\
\geq 1: 10\end{array}$ & $\begin{array}{r}23 \\
136\end{array}$ & $\begin{array}{r}19(82.6) \\
123(90.4)\end{array}$ & $\begin{array}{l}4(17.4) \\
13(9.6)\end{array}$ & 0.45 \\
\hline $\begin{array}{c}\text { T stage } \\
\text { T1-2 } \\
\text { T3-4 }\end{array}$ & $\begin{array}{r}37 \\
123\end{array}$ & $\begin{array}{r}30(81.1) \\
113(91.9)\end{array}$ & $\begin{aligned} 7(18.9) \\
10(8.1)\end{aligned}$ & 0.12 \\
\hline $\begin{array}{l}\text { N stage } \\
\text { N0-1 } \\
\text { N2-3 }\end{array}$ & $\begin{array}{l}71 \\
89\end{array}$ & $\begin{array}{l}62(87.3) \\
81(91.0)\end{array}$ & $\begin{array}{l}9(12.7) \\
8(9.0)\end{array}$ & 0.62 \\
\hline $\begin{array}{l}\text { TNM stage } \\
\text { I-II } \\
\text { III-IV }\end{array}$ & $\begin{array}{r}15 \\
145\end{array}$ & $\begin{array}{r}10(66.7) \\
133(91.7)\end{array}$ & $\begin{aligned} 5 & (33.3) \\
12 & (8.3)\end{aligned}$ & 0.01 \\
\hline
\end{tabular}

${ }^{\mathrm{a}}$ Fisher's exact test. ${ }^{\mathrm{b}} \mathrm{Mean} \pm \mathrm{SD}$. 'Student's t-test. TNM, tumor-node-metastasis.

$R A S$ mutants were observed to be absent in 65 NPC samples (17). KIT (v-kit Hardy-Zuckerman 4 feline sarcoma viral oncogene homolog) intron mutation was reported in NPC cell lines (21). Therefore, hotspot mutations in a group of actionable oncogenes remain to be investigated in larger studies.

In the present study, a high throughput OncoCarta ${ }^{\mathrm{TM}}$ ver. 1.0 mutation profiling panel was used to determine the prevalence of 238 hotspot mutations across 19 oncogenes in 8 NPC cell lines and 160 NPC patients. This panel interrogates with oncogenes with known targeted drugs or genes that interact with oncogenic pathways (22-24). Furthermore, the association between oncogene mutations and clinicopathological factors of NPC patients was also investigated in our study.

\section{Materials and methods}

Patient samples. The present study included 160 formalin-fixed paraffin-embedded (FFPE) tumor samples and matched peripheral blood cell samples from adult patients with newly diagnosed NPC. All samples were obtained from the Sun Yat-sen University Cancer Center between January 2006 and December 2009 and were collected before patients underwent treatment (radiotherapy or chemotherapy). All tissue slides were pathologically diagnosed by at least two independent pathologists according to the World Health Organization (WHO) classification (J.Z. and J.Y.).

The clinicopathological characteristics of all patients, including age, gender and clinical staging were collected and summarized in Table I. Clinical staging was classified according to the criteria of the 7th edition of the AJCC Cancer Staging Manual. The follow-up duration was calculated from the first day of treatment to either the day of death or the day of last examination. The median follow-up time was 40.0 months (range, 1.87-67.33). This study was approved by the Institutional Ethics Review Boards of Sun Yat-sen University Cancer Center and written informed consent was obtained from all patients. 
Table II. Mutations detected with the OncoCarta ${ }^{\mathrm{TM}}$ ver. 1.0 kit.

\begin{tabular}{|c|c|c|}
\hline No. & Genes & Targeted mutations \\
\hline 1 & ABL1 & D276G, E255K, E255V, F311L, F317L, F359V, G250E, H396R, M351T, Q252H, T315I, Y253F, Y253H \\
\hline 2 & AKT1 & E17del, E319G, L357P, P388T, Q43X, V167A, V167A, V461L \\
\hline 3 & AKT2 & R371H, S302G \\
\hline 4 & BRAF & $\begin{array}{l}\text { D594V, D594G, F468C, F595L, G464R, G464V, G464E, G466R, G469S, G469E, G469A, G469V, G469R, } \\
\text { G596R, K601E, K601N, L597Q, L597V, L597S, L597R, T599I, V600E, V600K }\end{array}$ \\
\hline 5 & CDK4 & $\mathrm{R} 24 \mathrm{C}, \mathrm{R} 24 \mathrm{H}$ \\
\hline 6 & EGFR & $\begin{array}{l}\text { A289V, D770_N771>AGG, D770_N771insG, E709A, E709G, E709V, E709K, E709H, E746_A750del, } \\
\text { E746_A750del, V ins, E746_A750del, T751A, E746_T751del, I ins, E746_T751del, S752D, E746_T751del, } \\
\text { V ins, G598V, G719A, G719S, G719C, H773_V774insH, H773_V774insNPH, H773>NPY, L747_E749del, } \\
\text { A750P, L747_S752del, P753S, L747_S752del, Q ins, L747_T750del, P ins, L747_T751del, L858R, L861Q, } \\
\text { M766_A767insAI, N771_P772>SVDNR, P772_H773insV, R108K, S752_I759del, S768I, SNP C2255T, } \\
\text { T263P, T751A, T790M, V769_D770insASV, V769_D770insCV, V774_C775insHV }\end{array}$ \\
\hline 7 & ERBB2 & A775_G776 ins YVMA, G776S, G776LC, G776VC, L755P, P780_Y781 insGSP, S779_P780 insVGS \\
\hline 8 & FGFR1 & $\mathrm{P} 252 \mathrm{~T}, \mathrm{~S} 125 \mathrm{~L}$ \\
\hline 9 & FGFR3 & A391E, G370C, K650Q, K650E, K650T, K650M, Y373C \\
\hline 10 & FLT3 & D835H, D835Y, I836del \\
\hline 11 & HRAS & G12V, G12D, G13C, G13R, G13S, Q61H, Q61H, Q61K, Q61L,Q61R, Q61P \\
\hline 12 & JAK2 & V617F \\
\hline 13 & KIT & $\begin{array}{l}\text { D52N, D579del, D816H, D816Y, D816V, E561K, E839K, F584S, K550_K558del, K558_E562del, } \\
\text { K558_V560del, K642E, L576P, M552L, P551_V555del, P585P, V559_V560del, V559D, V559A, V559G, } \\
\text { V559del, V559I, V560D, V560G, V560del, V825A, W557R, W557R, W557G, Y503_F504insAY, } \\
\text { Y553_Q556del, Y568D, Y570_L576del }\end{array}$ \\
\hline 14 & KRAS & $\begin{array}{l}\text { A59T, G12A, G12C, G12D, G12F, G12R, G12S, G12V, G13V, G13D, Q61E, Q61K, Q61H, Q61H, Q61L, } \\
\text { Q61R, Q61P }\end{array}$ \\
\hline 15 & MET & M1250T, R970C, T992I, Y1230C, Y1235D \\
\hline 16 & NRAS & $\begin{array}{l}\text { A18T, G12C, G12R, G12S, G12V, G12A, G12D, G13C, G13R, G13S, G13V, G13A, G13D, Q61E, Q61K, } \\
\text { Q61H, Q61L, Q61R, Q61P }\end{array}$ \\
\hline 17 & PDGFRA & $\begin{array}{l}\text { D1071N, D842_H845del, D842V, D846Y, F808L, I843_D846del, I843_S847>T, N870S, S566_E571>K, } \\
\text { T674I, V561D }\end{array}$ \\
\hline 18 & PIK3CA & $\begin{array}{l}\text { C420R, C901F, E542K, E545K, H1047R, H1047L, H701P, M1043I, M1043I, N345K, P539R, Q546K, } \\
\text { R38H, R88Q }\end{array}$ \\
\hline 19 & RET & A664D, C634R, C634W, C634Y, E632_L633del, M918T \\
\hline
\end{tabular}

Cell lines. The NPC cell lines SUNE-1, CNE-1, C666-1, CNE-2, HONE-1, HNE-1, 5-8F and 6-10B were obtained and maintained in RPMI-1640 (Invitrogen, Beijing, China) supplemented with $10 \%$ fetal bovine serum (Gibco, Montevideo, Uruguay) as previously described (25). The immortalized nasopharyngeal epithelial cell line (NP69) was cultured in keratinocyte serum-free medium (Invitrogen, NY, USA) supplemented with bovine pituitary extract (BD Biosciences, San Jose, CA, USA) (25). All cell lines were passaged for less than ten generations and incubated at $37^{\circ} \mathrm{C}$ in a $5 \% \mathrm{CO}_{2}$ incubator.

DNA extraction. For all FFPE tumor samples, hematoxylin and eosin (H\&E) stained slides were reviewed by two pathologists (Z.J. and J.Y.) to ensure a percentage of tumor cells $>70 \%$ as previously described $(26,27)$. Eight $10 \mu \mathrm{m}$ unstained FFPE tissue sections of each sample were deparaffinized by xylene wash $(20 \mathrm{~min}$ ) followed by two $100 \%$ ethanol washes. DNA was extracted from the pellets, cell lines and matched peripheral blood cell samples using the Qiagen DNA extraction Kits (Qiagen, Valencia, CA, USA) according to the manufacturer's instructions. The quality and quantity of DNA was determined using the NanoDrop ND1000 Spectrophotometer and gel agarose electrophoresis.

Oncogene mutation detection and analysis. DNA samples were amplified using the OncoCarta ${ }^{\mathrm{TM}}$ v1.0 Kit (Sequenom, San Diego, CA, USA) containing 24 pools of PCR primers and extension primers that allow the detection of 238 pathogenic mutations in 19 oncogenes ( $A B L 1, A K T 1, A K T 2, B R A F, C D K 4$, EGFR, ERBB2, FGFR1, FGFR3, FLT3, JAK2, KIT, MET, HRAS, KRAS, NRAS, PDGFA, PIK3CA and RET) (Table II) $(23,28)$. The extension products were analyzed based on the matrix-assisted laser desorption ionization-time of flight mass 
Table III. Summary of specific mutations detected in NPC samples using MassArray.

\begin{tabular}{|c|c|c|c|c|c|}
\hline \multirow[b]{2}{*}{ Gene } & \multirow[b]{2}{*}{ Mutation } & \multirow[b]{2}{*}{ Allele } & \multicolumn{2}{|c|}{ Allele frequency } & \multirow[b]{2}{*}{ Sample } \\
\hline & & & WT & Mut & \\
\hline AKT1 & E17K & $\mathrm{G}$ & 0.6 & 0.4 & 56 \\
\hline BRAF & $\begin{array}{l}\text { L597S } \\
\text { G469R }\end{array}$ & $\begin{array}{l}\mathrm{G} \\
\mathrm{T}\end{array}$ & $\begin{array}{l}0.77 \\
0.911\end{array}$ & $\begin{array}{l}0.23 \\
0.089\end{array}$ & $\begin{array}{r}17 \\
104\end{array}$ \\
\hline CDK4 & $\begin{array}{l}\mathrm{R} 24 \mathrm{H} \\
\mathrm{R} 24 \mathrm{C} \\
\mathrm{R} 24 \mathrm{C}\end{array}$ & $\begin{array}{l}\mathrm{T} \\
\mathrm{A} \\
\mathrm{A}\end{array}$ & $\begin{array}{l}0.73 \\
0.57 \\
0.868\end{array}$ & $\begin{array}{l}0.27 \\
0.43 \\
0.132\end{array}$ & $\begin{array}{r}17 \\
26 \\
116\end{array}$ \\
\hline EGFR & $\begin{array}{l}\text { N771_P772>SVDNR } \\
\text { N771_P772>SVDNR } \\
\text { T790M } \\
\text { H773_V774insNPH } \\
\text { R108K }\end{array}$ & $\begin{array}{c}\text { GCGT } \\
\text { GCGT } \\
\text { T } \\
\text { AA..AC } \\
\text { A }\end{array}$ & $\begin{array}{l}0.91 \\
0.83 \\
0.924 \\
0.909 \\
0.91\end{array}$ & $\begin{array}{l}0.09 \\
0.17 \\
0.076 \\
0.091 \\
0.09\end{array}$ & $\begin{array}{r}48 \\
106 \\
100 \\
104 \\
149\end{array}$ \\
\hline FGFR3 & Y373C & G & 0.85 & 0.15 & 26 \\
\hline KIT & $\begin{array}{l}\text { V559I } \\
\text { E839K } \\
\text { K558_V560del }\end{array}$ & $\begin{array}{c}\text { A } \\
\text { A } \\
\text { DEL }\end{array}$ & $\begin{array}{l}0.724 \\
0.901 \\
0.899\end{array}$ & $\begin{array}{l}0.276 \\
0.099 \\
0.101\end{array}$ & $\begin{array}{r}12 \\
104 \\
157\end{array}$ \\
\hline KRAS & $\begin{array}{l}\text { A59T } \\
\text { G12D }\end{array}$ & $\begin{array}{l}\mathrm{T} \\
\mathrm{T}\end{array}$ & $\begin{array}{l}0.89 \\
0.639\end{array}$ & $\begin{array}{l}0.11 \\
0.287\end{array}$ & $\begin{array}{r}13 \\
105\end{array}$ \\
\hline MET & $\begin{array}{l}\text { R970C } \\
\text { R970C }\end{array}$ & $\begin{array}{l}\mathrm{T} \\
\mathrm{T}\end{array}$ & $\begin{array}{l}0.92 \\
0.895\end{array}$ & $\begin{array}{l}0.08 \\
0.105\end{array}$ & $\begin{array}{r}17 \\
129\end{array}$ \\
\hline NRAS & $\mathrm{A} 18 \mathrm{~T}$ & $\mathrm{~T}$ & 0.89 & 0.12 & 13 \\
\hline PDGFRA & $\begin{array}{l}\text { T674I } \\
\text { T674I } \\
\text { T674I }\end{array}$ & $\begin{array}{l}\mathrm{T} \\
\mathrm{T} \\
\mathrm{T}\end{array}$ & $\begin{array}{l}0.85 \\
0.69 \\
0.94\end{array}$ & $\begin{array}{l}0.15 \\
0.31 \\
0.06\end{array}$ & $\begin{array}{l}14 \\
17 \\
96\end{array}$ \\
\hline PIK3CA & E545K & A & 0.894 & 0.106 & 153 \\
\hline
\end{tabular}

Mutations are represented as amino acidic changes found for each gene and the proportions between the wild type (WT) and mutated (Mut) alleles frequency for each alteration.

spectrometry (MALDI-TOF) technology on the Sequenom MassArray platform (28). The experiments were conducted according to the manufacturer's instructions, as previously described $(28,29)$. The spectra were analyzed by MassArray Typer Analyzer ${ }^{\circledR}$ ver. 4.0.4.20 Software (Sequenom) which automates the identification of mutants by comparing ratios of wild-type (WT) peaks to all suspected mutants and adjusting these peaks when adducts are detected in the spectrum. All mutations detected were manually reviewed by three different persons (N.J., N.L. and F.Y.). Mutation peaks that appeared in both tumor and matched blood cell DNA were not considered as somatic mutations and were excluded from further analysis.

Statistical analysis. Statistical analyses were conducted using SPSS ver. 20 Software. The $\chi^{2}$ test and Fisher's exact test were used to assess differences in the distribution of clinical variables and oncogene mutation status. Kaplan-Meier analysis was used to determine survival; the differences between genotypes were compared using the log-rank test. HR values were calculated using univariate Cox regression analysis. Multivariate Cox regression analysis was used to test the independent significance, in which KIT mutation, age, gender, $\mathrm{T}$ and $\mathrm{N}$ stages were used as covariates. All tests were two-tailed, and P-values $<0.05$ were considered to indicate a statistically significant difference.

\section{Results}

Oncogene mutations detected in NPC. Of the 160 NPC patients, $17(10.6 \%)$ had at least one oncogene mutation and $4(23.5 \%)$ of them had two or more mutations. In total, we identified 24 mutations located in 11 genes by Sequenom OncoCarta kit (Table III). EGFR variants were detected in 5 tumors, followed by $C D K 4, K I T$ and PDGFRA mutations in 3 patients and KRAS, BRAF and MET (MET proto-oncogene) mutations in 2 patients. FGFR3 (fibroblast growth factor receptor 3), $A K T 1$ (v-akt murine thymoma viral oncogene homolog 1), PIK3CA and NRAS mutations were only detected in one sample (Table III). We did not detect any mutations in the remaining eight oncogenes. Patients with $B R A F$ mutations were WT in KRAS, which was consistent with previous findings in colon cancer (30). Direct sequencing was adopted to validate the MassArray findings. Representative figures of detected mutations are shown in Fig. 1A and B. 
$\mathbf{A}$

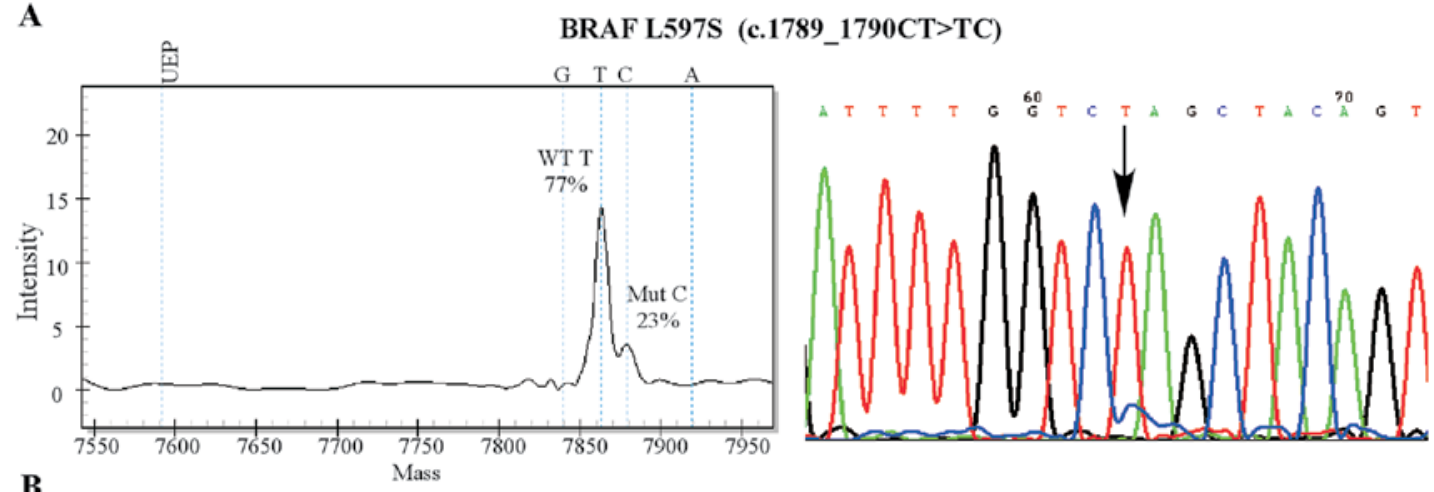

B
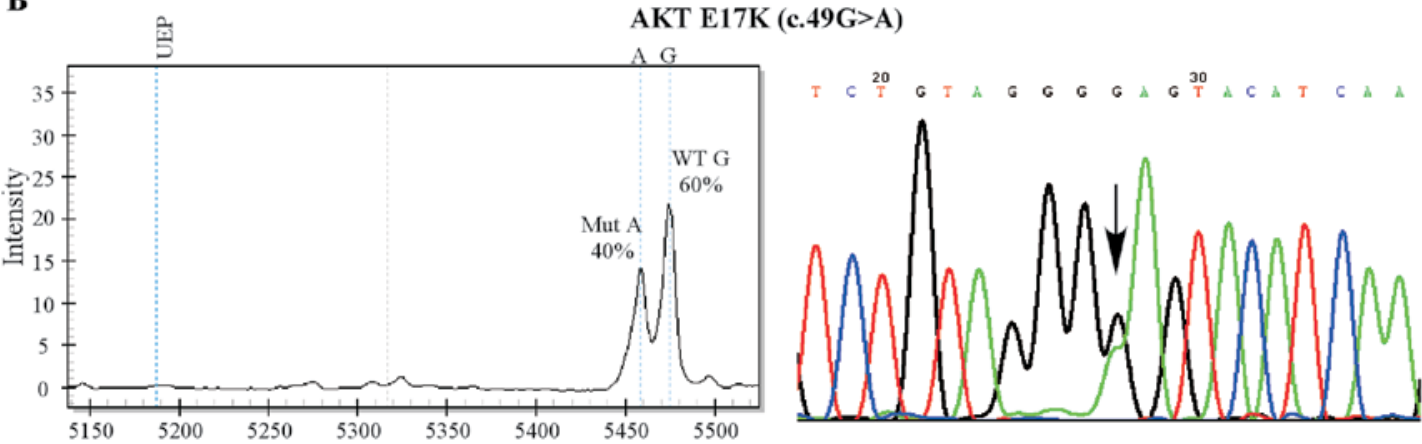

Figure 1. Representative examples of mutations detected by MassArray and DNA direct sequencing. (A and B) The expected positions for the unextended primer (UEP), and the extension products (mutant and WT) from assays AKT1_7 and BRAF_12-13 by MassArray indicated in the left panel. The proportion of peak areas and the specific base are also shown. BRAF L597S (c.1789_1790CT>TC) and AKT1 E17K (c.49G>A) mutations were confirmed by direct sequencing (black arrows indicate the mutation site in the right panel of A and B).

We next determined the 238 hotspot mutations in 8 NPC cell lines: 5-8F, 6-10B, SUNE-1, CNE-1, C666-1, CNE-2, HONE-1 and HNE-1. PIK3CA c.3140A $>\mathrm{G}(\mathrm{H} 1047 \mathrm{R})$ was the only mutation observed in 7 NPC cell lines, but not in C666-1 (Fig. 2). The results were confirmed by direct sequencing (Fig. 3). Notably, the PIK3CA c.3140A $>$ G mutation was also found absent in an immortalized nasopharyngeal epithelial cell line NP69 by direct sequencing (Fig. 3).

Taken together, hotspot oncogene mutations which are common in other solid tumors are infrequent events in NPC.

Correlation between mutational profile and clinicopathological characteristics. The relationship between clinicopathological factors and mutation patterns were assessed. As shown in Table I, oncogene mutations were significantly associated with the TNM stage of NPC patients $(\mathrm{P}=0.01)$. However, there was no association between oncogene mutations and clinical characteristics such as age, gender, histopathological grade, EBV-related antigen levels, tumor (T) and lymph node $(\mathrm{N})$ stage of NPC patients $(\mathrm{P}>0.05$, Table $\mathrm{I})$. We also did not find any difference in risk habits (smoking or alcohol consumption) in patients with or without oncogene mutations $(\mathrm{P}>0.05$, Table I).

Furthermore, Kaplan-Meier analysis did not show significant differences in overall survival (OS) and relapse-free survival (RFS) between patients with and without oncogene mutations ( $\mathrm{P}>0.05$ ) (Fig. 4A). Patients with KIT mutation were associated with poorer OS (HR, 8.34; 95\% CI, 2.47-28.21; $\mathrm{P}<0.001)$ and RFS (HR, 8.20; 95\% CI, 1.03-64.92; $\mathrm{P}=0.02)$ (Fig. 4B). Furthermore, we performed multivariate analyses with KIT mutation, age, gender, $\mathrm{T}$ and $\mathrm{N}$ stages as covariates
Table IV. Summary of the multivariable analysis of prognostic factors for overall survival and risk score in NPC.

\begin{tabular}{lccc}
\hline Variables & P-value & HR & $95 \%$ CI \\
\hline $\begin{array}{l}\text { Age group (years) } \\
\text { ( } 47 \text { vs. >47) }\end{array}$ & 0.01 & 1.69 & $1.11-2.58$ \\
$\begin{array}{l}\text { Gender } \\
\text { (Male vs. female) }\end{array}$ & 0.06 & 0.58 & $0.32-1.02$ \\
$\begin{array}{l}\text { T stage } \\
\text { (T3-T4 vs. T1-T2) }\end{array}$ & 0.18 & 1.42 & $0.85-2.37$ \\
$\begin{array}{l}\text { N stage } \\
\text { N2-N3 vs. N1-N0) }\end{array}$ & 0.04 & 1.56 & $1.02-2.41$ \\
KIT mutation & $<0.01$ & 5.94 & $1.73-20.42$ \\
\hline
\end{tabular}

$(\mathrm{P}<0.05)$. We found that the KIT mutation (HR, 5.94; 95\% CI, 1.73-20.42; $\mathrm{P}<0.01$ ), age (HR, 1.69; 95\% CI, 1.11-2.58; $\mathrm{P}=0.01$ ) and $\mathrm{N}$ stage (HR, 1.56 ; 95\% CI, 1.02-2.41; $\mathrm{P}=0.04)$ were independent prognostic factors associated with OS in NPC patients (Table IV).

\section{Discussion}

In recent years, identification of somatic mutations as key perturbations that promote tumorigenesis has become an essential component in determining the management of certain malignancies. For example, oncogenic mutations in $E G F R, K R A S$ have been clinically used as target and sensi- 

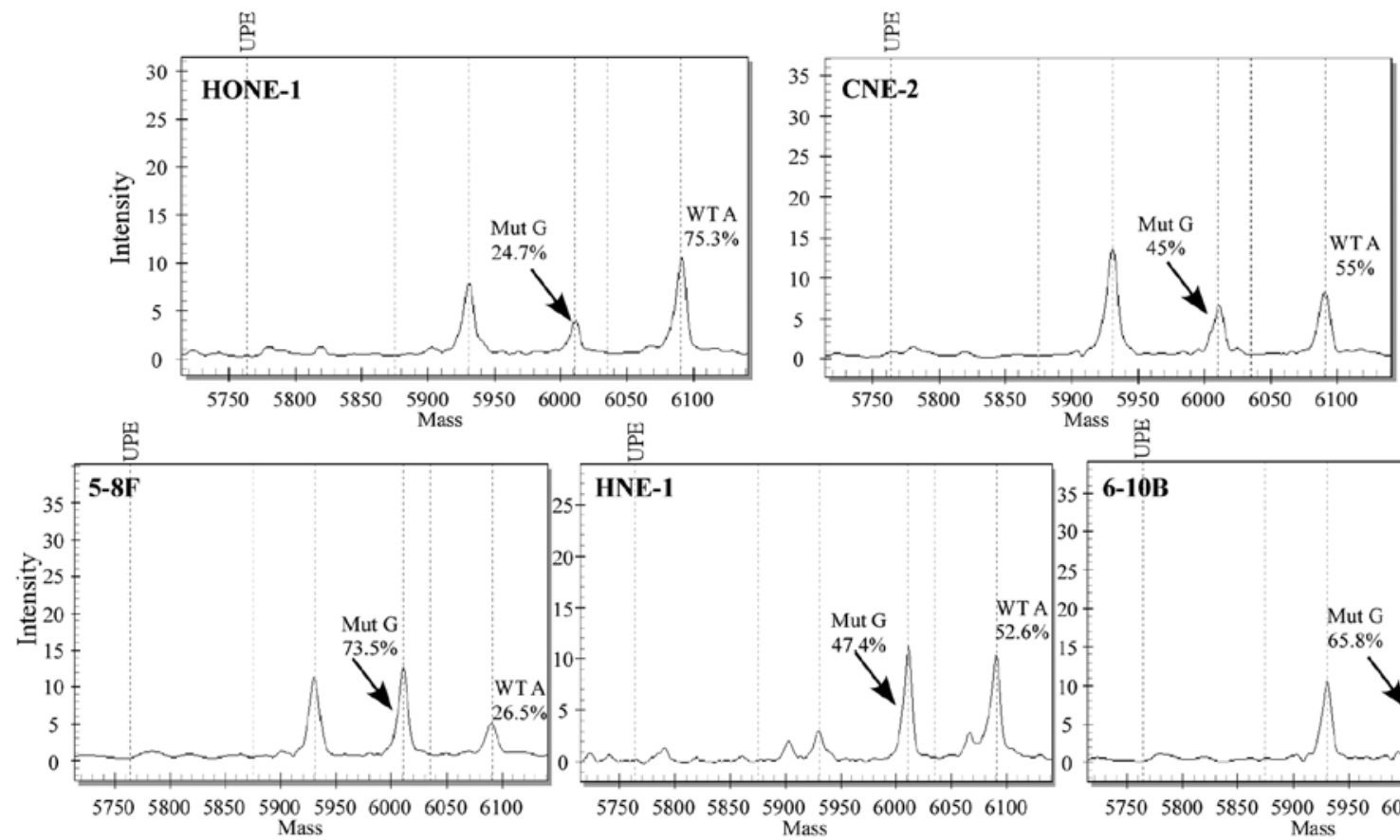

空

Mass tran
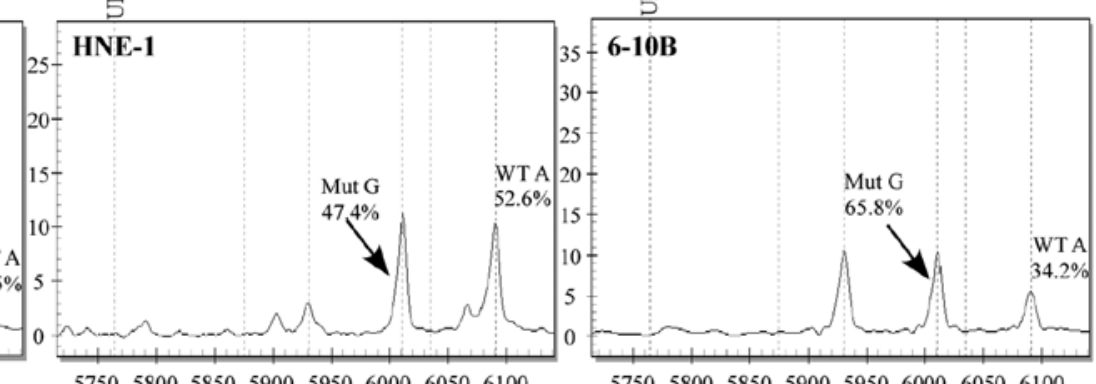

Mas

$\begin{array}{ccccc}575058005850 & 5900595060006050 \quad 6100 \\ \text { Mass }\end{array}$

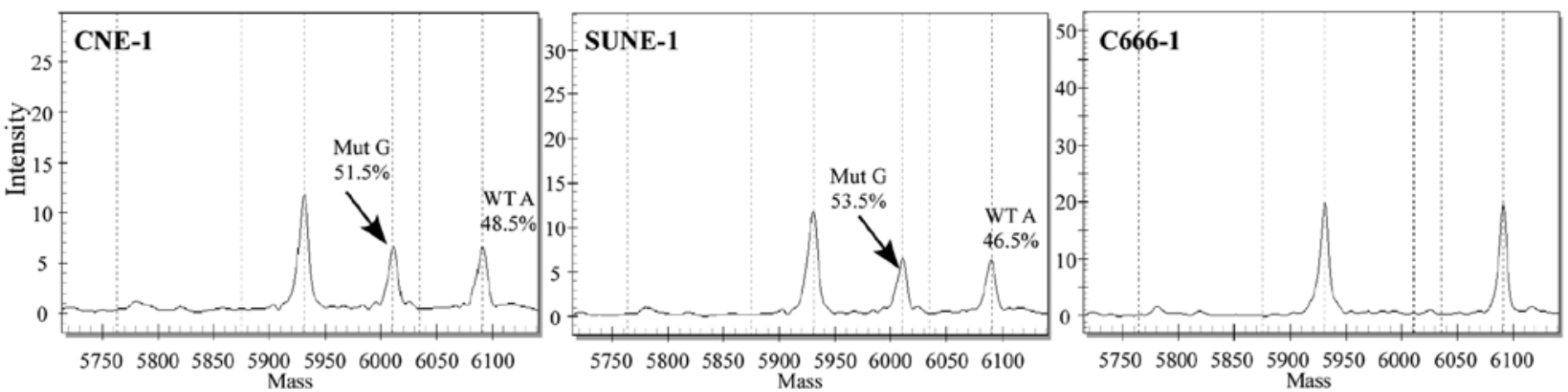

Figure 2. Seven NPC cell lines showing PIK3CA H1047R mutation. The expected peak positions for the UEP and the extension products (Mutant G and WT A) using the PIK3CA_9 assay in HONE-1, CNE-2, 5-8F, HNE-1, 6-10B, CNE1, SUNE1 and C666-1 cell lines are shown. The arrows indicate the mutation peaks. Other peaks included in these spectra that were not marked are results of multiplexing but not part of the designated assays.

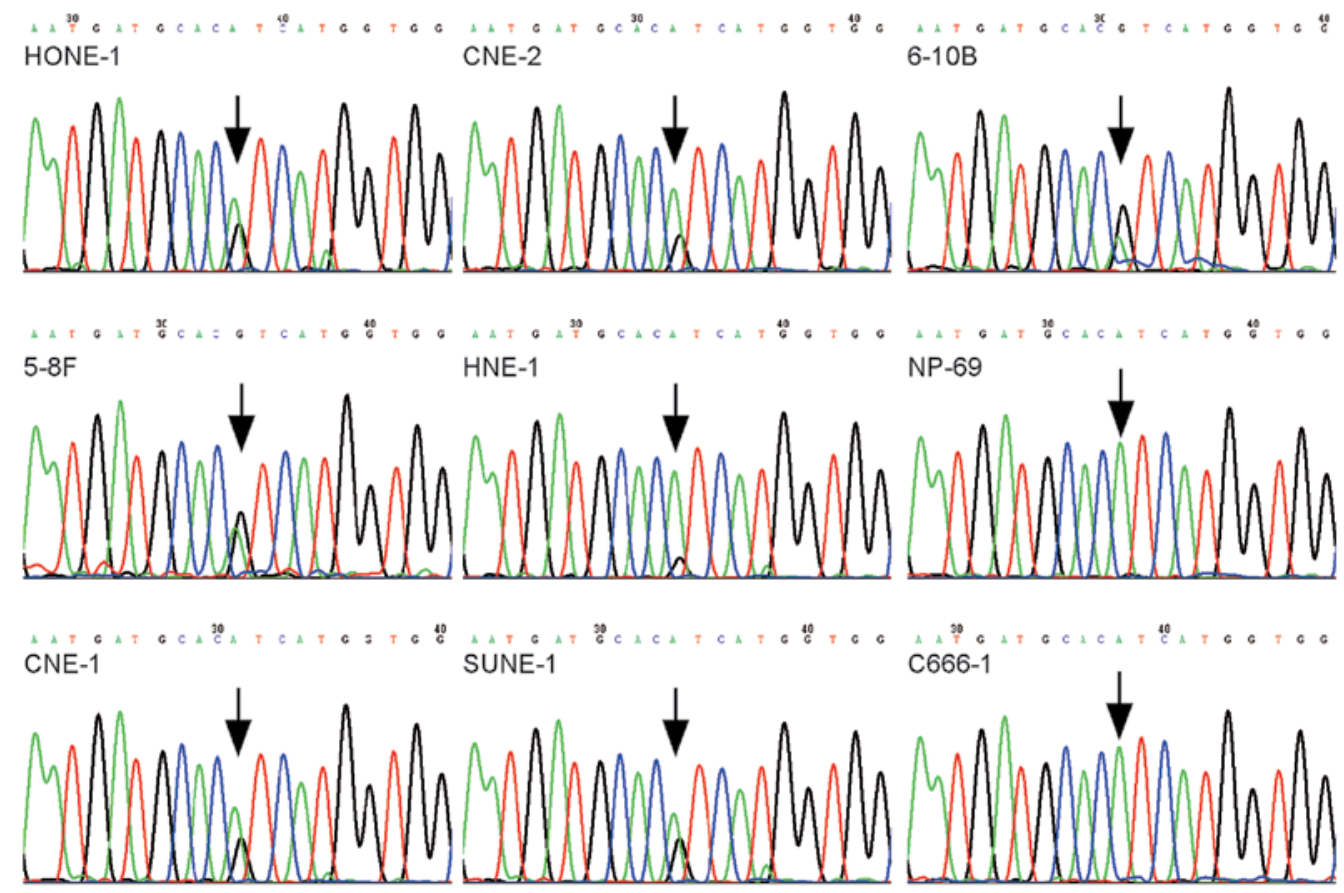

Figure 3. PIK3CA H1047R mutation confirmed in NPC cell lines by direct sequencing. PIK3CA H1047R mutation was confirmed by direct sequencing in 8 NPC cell lines and a normal nasopharyngeal epithelial cell line NP69 (black arrows indicate the mutation site). 

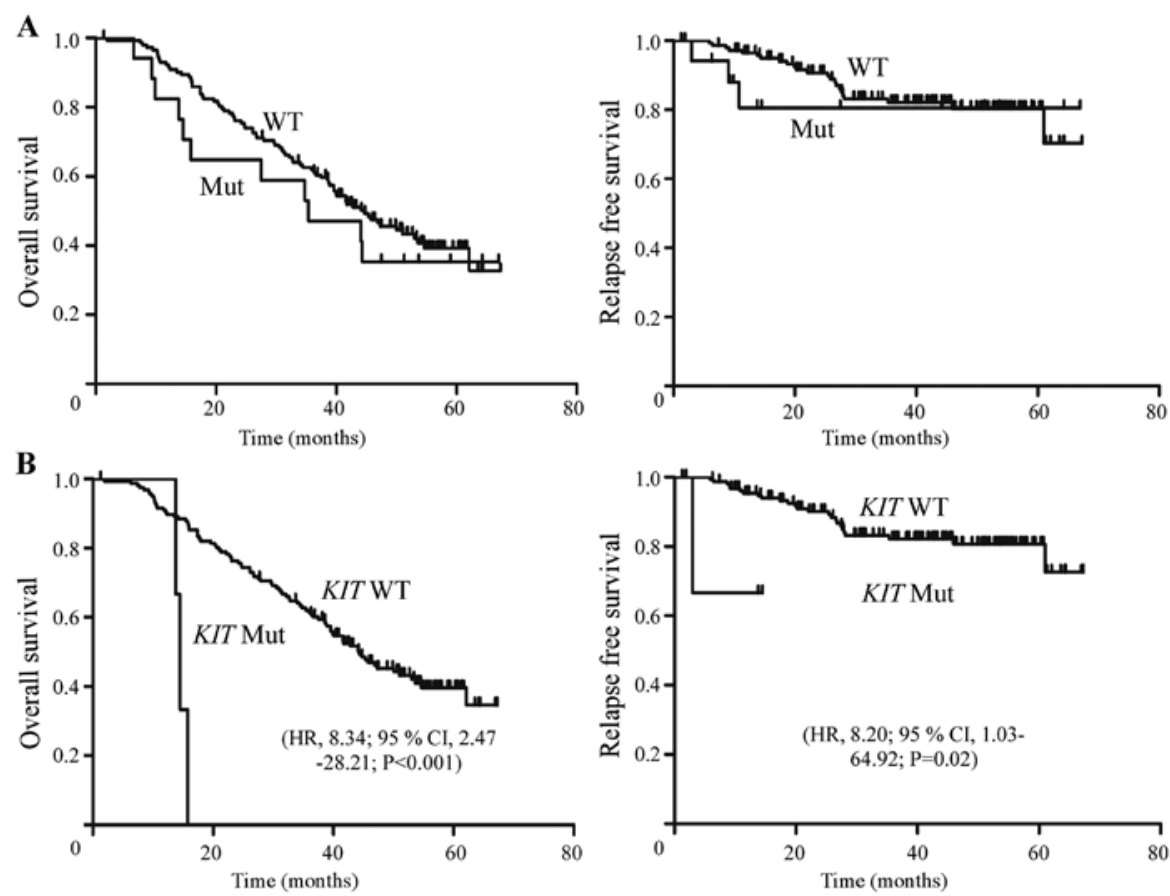

Figure 4. KIT mutations correlate with poorer survival in NPC patients. Kaplan-Meier curves of overall survival (OS) and relapse-free survival (RFS) in NPC patients stratified by mutation levels with respect to over time. Hazard ratio (HR) values and confidence interval (CI) were calculated by the univariate Cox regression analysis. (A) There was no significant difference in OS and RFS between NPC patients with or without mutations. (B) Patients with KIT mutations exhibited poorer OS and RFS in comparison with KIT WT patients.

tivity biomarkers in the treatment of non-small cell lung carcinoma (31). However, knowledge regarding oncogene mutational patterns in NPC remains limited, especially in patients from NPC prevalent southern China. Thus, a highthroughput OncoCarta panel was adopted in the current study to determine 238 hotspot mutations across 19 oncogenes in NPC. This panel provides a cost effective and efficient technology for detecting known hotspot mutations in FFPE samples $(23,32)$. Moreover, information concerning 10 of the 19 oncogenes investigated by the OncoCarta ${ }^{\mathrm{TM}}$ ver. 1.0 assay is either limited or absent in COSMIC database in NPC (http://www.sanger.ac.uk/cosmic).

The present study demonstrated that oncogene mutations were uncommon in NPC with $10.6 \%$ of patients carrying one or more mutations across 11 oncogenes. There was no difference between patients with or without oncogene mutations in risk habits (tobacco and alcohol consumption) and EBV infection status, both of which are historically associated with NPC. Consistent with previous reports, known PIK3CA mutations were detected in both NPC cell lines and tissues with similar mutation frequency compared to COSMIC database (Table V) $(17,33)$. Furthermore, we found a correlation between KIT mutation and poorer survival in NPC patients. KIT mutation together with age and $\mathrm{N}$ stage were independent prognostic factors for NPC. The identification of mutated oncogenes in NPC is encouraging as it may provide insight into the etiology of NPC and influence future clinical management.

PIK3CA, BRAF, EGFR, KIT, KRAS, HRAS, NRAS, $P D G F R A$ and MET (34) oncogenes have been previously reported to be absent in NPC according to the COSMIC database, whereas mutations in gene $A K T 1, C D K 4, F G F R 3$ and $A B L 1$ have not yet been studied in NPC (Table V) (35). In the
Table V. Mutations detected in the present study compared with the COSMIC database.

\begin{tabular}{lcc}
\hline Genes & $\begin{array}{c}\text { COSMIC database } \\
\text { Mut/total cases }(\%)^{\mathrm{a}}\end{array}$ & $\begin{array}{c}\text { Present study } \\
\text { Mut cases }(\% ; \mathrm{n}=168)^{\mathrm{a}}\end{array}$ \\
\hline AKT1 & $\mathrm{N}$ & $1(0.6)$ \\
BRAF & $0 / 65(0)$ & $2(1.2)$ \\
CDK4 & $\mathrm{N}$ & $3(1.8)$ \\
EGFR & $0 / 78(0)$ & $5(3.0)$ \\
FGFR3 & $\mathrm{N}$ & $1(0.6)$ \\
KIT & $0 / 3(0)$ & $3(1.8)$ \\
KRAS & $0 / 74(0)$ & $2(1.2)$ \\
MET & $0 / 5(0)$ & $2(1.2)$ \\
NRAS & $0 / 18(0)$ & $1(0.6)$ \\
PDGFRA & $0 / 3(0)$ & $3(1.8)$ \\
PIK3CA & $8 / 105(7.6)$ & $9(5.4)$ \\
\hline
\end{tabular}

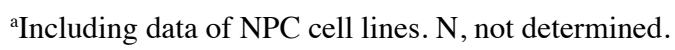

present study, mutations in these oncogenes were reported in NPC for the first time. This could be explained by the use of a more sensitive MALDI-TOF technology which is as sensitive as next generation sequencing, and more sensitive than Sanger sequencing, as Su et al demonstrated (36). Secondly, according to the COSMIC database, most of the previous studies were based on cohorts $<100$ samples (Table V). Furthermore, this difference may also be due to different pathological characteristics or population background. 
The PIK3CA gene encodes the $110 \mathrm{kDa}$ catalytic subunit of PI3K. Upon activation, PIK3CA generates an activating signaling cascade involved in cell growth, survival, proliferation, motility and morphology $(37,38)$. A study by Or et al previously reported a one base substitution of c.3140A $>\mathrm{G}$ (H1047R) in the PIK3CA gene in CNE-2 and HONE-1, but not in C666-1 cells line (33). We confirmed the same mutant in 7 NPC cell lines, including CNE-2 and HONE-1. However, EBV positive C666-1 and an immortalized nasopharyngeal epithelial cell line NP69 showed absence of this mutation. Since the c.3140A $>\mathrm{G}$ mutant acts as a gain-of-function mutation in PIK3CA kinase domain (39) and appears only in EBV negative NPC cell lines, we speculate that this mutation may play an important role in the transformation of EBV-negative NPC cell lines, which deserves further investigation. We did not find this mutant in 160 patient samples among which $98.1 \%$ of patients showed detectable EBV-related antigens. Instead, a PIK3CA c.1633G >A (E545K) mutation was detected in one NPC patient. This mutant was previously reported by Chou et al in 4 NPC patients (17). Moreover, in comparison with the mutation rate of $7.6 \%(8 / 105)$ reported by COSMIC database (including cell line data), this study found a similar mutation frequency of $5.6 \%(8 / 168)$ in PIK3CA oncogene (Table V) $(18,33,40)$.

The proto-oncogene $c$-KIT encodes a transmembrane tyrosine kinase receptor which plays important roles in the hematogenous system, placenta, heart, lung, and midgestational kidney $(41,42)$. Gain-of-function mutations of the $c-K I T$ gene promote constitutive phosphorylation of KIT and, consequently, activation of downstream PI3K/AKT, Src family kinases and MAPK pathways (42). In our study, we found KIT K558_V560del, E839K and V559I mutations in three NPC patients. K558_V560del and V559I are juxtamembrane mutations located in exon 11 of KIT oncogene which have been observed in GISTs $(43,44)$ and aggressive systemic mastocytosis (ASM), respectively (44). These two mutants showed spontaneous KIT phosphorylation (45) and could transform IL-3-dependent Ba/F3 cells into IL-3-independent growth in the absence of KIT ligand stem cell factor (SCF) (46). In contrast, $\mathrm{KIT}^{\mathrm{E} 839 \mathrm{~K}}$ was not spontaneously phosphorylated in response to exogenous SCF and thus lacked cell transforming ability (45). KIT phosphorylated mutants could be inhibited by KIT inhibitors such as imatinib and dasatinib (47). These data together with our findings that KIT mutation correlated with poor survival in NPC, suggest that targeting KIT could be a potential therapeutic strategy in the treatment of NPC. We did not find any KIT mutation in NPC cell lines. This is consistent with a study by Huang et al (21) in which no KIT exon 9-21 hotspot mutation was found in 5 NPC cell lines. However, the fact that KIT mutation was only detected in $3 / 160$ NPC patients requires broader studies in the future. KIT DNA amplification, protein overexpression and their clinical relevance also warrants further investigation in NPC.

Mutations in exon 18-21 of EGFR tyrosine kinase domain are present in lung cancer, and some of them are related to response to anti-EGFR agents such as gefitinib or erlotinib $(8,24)$. EGFR tyrosine kinase domain mutations have been previously found absent in 60 Moroccan patients (20) and four NPC cell lines (48). In our series, we detected five NPC cases carrying four EGFR mutants (Table III). EGFR T790M,
H773_V774insNPH and N771_P772>SVDNR mutations located in EGFR exon 20 could change the crystal structures of EGFR which lead to resistance to EGFR inhibitors (49). EGFR R108K is a gain-of-function mutation in EGFR exon 3 which has been reported in glioma. It would be of interest to determine whether these mutants affect the response to EGFR-TKIs in NPC patients in the future.

In the present study, we first reported three $C D K 4$ mutations in NPC. Cyclin-dependent kinase 4 (CDK4) is the chief catalytic subunit of the regulatory cyclin $\mathrm{D}$ that governs G1-to-S phase cell cycle progression (50). Dominant activating mutations affecting codon 24 of the $C D K 4$ gene (R24H or $\mathrm{R} 24 \mathrm{C}$ ) render CDK4 insensitive to p16INK4 inhibition and are responsible for multiple neoplasia developing $(50,51)$. Collectively, these data indicated that $C D K 4$ mutation may play a role in oncogenesis in a subset of NPC patients. Moreover, mutations affect the RAS/RAF pathway and growth factor receptors such as MET, PDGFRA, FGFR3 were also found in NPC in our study. Since all these molecules are popular targets in anticancer treatment, NPC patients with these mutations may benefit from therapies targeting these oncogenes

In summary, this study provided evidence for understanding oncogenic mutational patterns in NPC. Our data showed lower oncogene mutation frequencies in NPC compared to other solid tumors (52-55). The presence of mutations in a few key oncogenes may ultimately be important in clinical management of NPC and requires future verification.

\section{Acknowledgements}

The authors thank Professor Feng Chen (Department of Epidemiology and Biostatistics, School of Public Health, Nanjing Medical University, Nanjing, Jiangsu, China) for helpful discussion and assistance. This research was supported by grants from the Guangdong Province Universities and Colleges Pearl River Scholar Funded Scheme (2010), the National Natural Science Foundation of China (no. 81230056), the Innovation Team Development Plan of the Ministry of Education (no. IRT1297), the Science and Technology Project of Guangzhou City, China (no. 12BppZXaa2060002) and Guangdong Translational Medicine Public Platform (no. 4202037).

\section{References}

1. Jemal A, Bray F, Center MM, Ferlay J, Ward E and Forman D: Global cancer statistics. CA Cancer J Clin 61: 69-90, 2011.

2. Lee AW, Sze WM, Au JS, et al: Treatment results for nasopharyngeal carcinoma in the modern era: the Hong Kong experience. Int J Radiat Oncol Biol Phys 61: 1107-1116, 2005.

3. Wee J, Tan EH, Tai BC, et al: Randomized trial of radiotherapy versus concurrent chemoradiotherapy followed by adjuvant chemotherapy in patients with American Joint Committee on Cancer/International Union against cancer stage III and IV nasopharyngeal cancer of the endemic variety. J Clin Oncol 23: 6730-6738, 2005.

4. Bensouda Y, Kaikani W, Ahbeddou N, et al: Treatment for metastatic nasopharyngeal carcinoma. Eur Ann Otorhinolaryngol Head Neck Dis 128: 79-85, 2011

5. Caponigro F, Longo F, Ionna F and Perri F: Treatment approaches to nasopharyngeal carcinoma: a review. Anticancer Drugs 21: 471-477, 2010.

6. Ma BB and Chan AT: Systemic treatment strategies and therapeutic monitoring for advanced nasopharyngeal carcinoma. Expert Rev Anticancer Ther 6: 383-394, 2006. 
7. Vogelstein B and Kinzler KW: Cancer genes and the pathways they control. Nat Med 10: 789-799, 2004.

8. Lynch TJ, Bell DW, Sordella R, et al: Activating mutations in the epidermal growth factor receptor underlying responsiveness of non-small-cell lung cancer to gefitinib. N Engl J Med 350: 2129-2139, 2004

9. Shaw AT, Yeap BY, Mino-Kenudson M, et al: Clinical features and outcome of patients with non-small-cell lung cancer who harbor EML4-ALK. J Clin Oncol 27: 4247-4253, 2009.

10. Misale S, Yaeger R, Hobor S, et al: Emergence of KRAS mutations and acquired resistance to anti-EGFR therapy in colorectal cancer. Nature 486: 532-536, 2012.

11. Bardelli A and Janne PA: The road to resistance: EGFR mutation and cetuximab. Nat Med 18: 199-200, 2012.

12. Klein G: Nasopharyngeal carcinoma (NPC) is an enigmatic tumor. Semin Cancer Biol 12: 415-418, 2002.

13. Hui AB, Lo KW, Leung SF, et al: Detection of recurrent chromosomal gains and losses in primary nasopharyngeal carcinoma by comparative genomic hybridisation. Int J Cancer 82: 498-503, 1999.

14. Fan CS, Wong N, Leung SF, et al: Frequent c-myc and Int-2 overrepresentations in nasopharyngeal carcinoma. Hum Pathol 31 $169-178,2000$

15. Hui AB, Lo KW, Teo PM, To KF and Huang DP: Genome wide detection of oncogene amplifications in nasopharyngeal carcinoma by array based comparative genomic hybridization. Int J Oncol 20: 467-473, 2002.

16. Forbes SA BG, Bamford S, Dawson E, Kok C, Clements J, Menzies A, Teague JW, Futreal PA and Stratton MR: The Catalogue of Somatic Mutations in Cancer (COSMIC). Curr Protoc Hum Genet: Chapter 10, 2008.

17. Chou CC, Chou MJ and Tzen CY: PIK3CA mutation occurs in nasopharyngeal carcinoma but does not significantly influence the disease-specific survival. Med Oncol 26: 322-326, 2009.

18. Yip WK, Leong VC, Abdullah MA, Yusoff S and Seow HF: Overexpression of phospho-Akt correlates with phosphorylation of EGF receptor, FKHR and BAD in nasopharyngeal carcinoma. Oncol Rep 19: 319-328, 2008.

19. Fendri A, Khabir A, Mnejja W, et al: PIK3CA amplification is predictive of poor prognosis in Tunisian patients with nasopharyngeal carcinoma. Cancer Sci 100: 2034-2039, 2009.

20. Naji F, Attaleb M, Laantri N, et al: Identification of G2607A mutation in EGFR gene with a significative rate in Moroccan patients with nasopharyngeal carcinoma. Cell Mol Biol 56: OL1442-OL1446, 2010.

21. Huang PY, Hong MH, Zhang X, Mai HQ, Luo DH and Zhang L: C-KIT overexpression and mutation in nasopharyngeal carcinoma cell lines and reactivity of Imatinib on these cell lines. Chin J Cancer 29: 131-135, 2010.

22. Ding L, Getz G, Wheeler DA, et al: Somatic mutations affect key pathways in lung adenocarcinoma. Nature 455: 1069-1075, 2008.

23. Fumagalli D, Gavin PG, Taniyama Y, et al: A rapid, sensitive, reproducible and cost-effective method for mutation profiling of colon cancer and metastatic lymph nodes. BMC Cancer 10: 101, 2010.

24. Pao W and Girard N: New driver mutations in non-small-cell lung cancer. Lancet Oncol 12: 175-180, 2011.

25. Liu N, Tang LL, Sun Y, et al: MiR-29c suppresses invasion and metastasis by targeting TIAM1 in nasopharyngeal carcinoma. Cancer Lett 329: 181-188, 2013.

26. Wetterskog D, Lopez-Garcia MA, Lambros MB, et al: Adenoid cystic carcinomas constitute a genomically distinct subgroup of triple-negative and basal-like breast cancers. J Pathol 226: 84-96, 2012.

27. Duprez R, Wilkerson PM, Lacroix-Triki M, et al: Immunophenotypic and genomic characterization of papillary carcinomas of the breast. J Pathol 226: 427-441, 2012.

28. Thomas RK, Baker AC, Debiasi RM, et al: High-throughput oncogene mutation profiling in human cancer. Nat Genet 39 : $347-351,2007$

29. Pearce M, Hogg G, Hosseni D and Ehrich M: Mutation profiling in tumor samples using the Sequenom OncoCarta ${ }^{\mathrm{TM}}$ Panel Nature Methods 6: vii-viii, 2009.

30. Jhawer M, Goel S, Wilson AJ, et al: PIK3CA mutation/PTEN expression status predicts response of colon cancer cells to the epidermal growth factor receptor inhibitor cetuximab. Cancer Res 68: 1953-1961, 2008

31. Cappuzzo F, Ciuleanu T, Stelmakh L, et al: Erlotinib as maintenance treatment in advanced non-small-cell lung cancer: a multicentre, randomised, placebo-controlled phase 3 study. Lancet Oncology 11: 521-529, 2010.
32. Tie J, Lipton L, Desai J, et al: KRAS mutation is associated with lung metastasis in patients with curatively resected colorectal cancer. Clin Cancer Res 17: 1122-1130, 2011.

33. Or YY, Hui AB, To KF, Lam CN and Lo KW: PIK3CA mutations in nasopharyngeal carcinoma. Int J Cancer 118: 1065-1067, 2006.

34. Qian CN, Guo X, Cao B, et al: Met protein expression level correlates with survival in patients with late-stage nasopharyngeal carcinoma. Cancer Res 62: 589-596, 2002.

35. Forbes SA, Bindal N, Bamford S, et al: COSMIC: mining complete cancer genomes in the Catalogue of Somatic Mutations in Cancer. Nucleic Acids Res 39: D945-D950, 2011.

36. Su KY, Chen HY, Li KC, et al: Pretreatment epidermal growth factor receptor (EGFR) T790M mutation predicts shorter EGFR tyrosine kinase inhibitor response duration in patients with nonsmall-cell lung cancer. J Clin Oncol 30: 433-440, 2012.

37. Shayesteh L, Lu Y, Kuo WL, et al: PIK3CA is implicated as an oncogene in ovarian cancer. Nat Genet 21: 99-102, 1999.

38. Cantley LC: The phosphoinositide 3-kinase pathway. Science 296: 1655-1657, 2002

39. Kang S, Bader AG and Vogt PK: Phosphatidylinositol 3-kinase mutations identified in human cancer are oncogenic. Proc Nat Acad Sci USA 102: 802-807, 2005.

40. Abers GA, Ferris A, Craig M, et al: Mantle compensation of active metamorphic core complexes at Woodlark rift in Papua New Guinea. Nature 418: 862-865, 2002.

41. Qiu FH, Ray P, Brown K, et al: Primary structure of c-kit: relationship with the CSF-1/PDGF receptor kinase family - oncogenic activation of $\mathrm{v}$-kit involves deletion of extracellular domain and C terminus. EMBO J 7: 1003-1011, 1988.

42. Phung B, Sun J, Schepsky A, Steingrimsson E and Ronnstrand L: C-KIT signaling depends on microphthalmia-associated transcription factor for effects on cell proliferation. PLoS One 6: e24064, 2011.

43. Orfao A, Garcia-Montero AC, Sanchez L, Escribano L and REMA: Recent advances in the understanding of mastocytosis: the role of KIT mutations. Br J Haematol 138: 12-30, 2007.

44. Nakagomi N and Hirota S: Juxtamembrane-type c-kit gene mutation found in aggressive systemic mastocytosis induces imatinib-resistant constitutive KIT activation. Lab Invest 87: 365-371, 2007.

45. Longley BJ Jr., Metcalfe DD, Tharp M, et al: Activating and dominant inactivating c-KIT catalytic domain mutations in distinct clinical forms of human mastocytosis. Proc Natl Acad Sci USA 96: 1609-1614, 1999.

46. Growney JD, Clark JJ, Adelsperger J, et al: Activation mutations of human c-KIT resistant to imatinib mesylate are sensitive to the tyrosine kinase inhibitor PKC412. Blood 106: 721-724, 2005.

47. Lennartsson J and Rönnstrand L: Stem cell factor receptor/c-Kit: from basic science to clinical implications. Physiol Rev 92: $1619-1649,2012$

48. Ma BB, Lui VW, Poon FF, et al: Preclinical activity of gefitinib in non-keratinizing nasopharyngeal carcinoma cell lines and biomarkers of response. Invest New Drugs 28: 326-333, 2010.

49. Yasuda H, Kobayashi S and Costa DB: EGFR exon 20 insertion mutations in non-small-cell lung cancer: preclinical data and clinical implications. Lancet Oncol 13: e23-e31, 2012.

50. Rane SG, Cosenza SC, Mettus RV and Reddy EP: Germ line transmission of the Cdk4(R24C) mutation facilitates tumorigenesis and escape from cellular senescence. Mol Cell Biol 22: 644-656, 2002

51. Vax VV, Bibi R, Diaz-Cano S, et al: Activating point mutations in cyclin-dependent kinase 4 are not seen in sporadic pituitary adenomas, insulinomas or Leydig cell tumours. J Endocrinol 178: 301-310, 2003.

52. Brose MS, Volpe P, Feldman M, et al: BRAF and RAS mutations in human lung cancer and melanoma. Cancer Res 62: 6997-7000, 2002.

53. Davies H, Bignell GR, Cox C, et al: Mutations of the BRAF gene in human cancer. Nature 417: 949-954, 2002.

54. Kobayashi S, Boggon TJ, Dayaram T, et al: EGFR mutation and resistance of non-small-cell lung cancer to gefitinib. N Engl J Med 352: 786-792, 2005.

55. Paez JG, Jänne PA, Lee JC, et al: EGFR mutations in lung cancer: correlation with clinical response to gefitinib therapy. Science 304: 1497-1500, 2004. 